\title{
Case Report: Evaluate Management Performance and the Degree of Readiness Hospital Emergency in Critical Situations
}

\author{
Asma Bahranifard $^{1 *}$ (D), Kobra Rahzani ${ }^{(D)}$, Ali Akbar Maleki Rad ${ }^{3}$ (D), Mokhtar Malekpour ${ }^{1}$ (D) \\ 1. Department of Crisis Management, School of Natural Hazard Management, University of Isfahan, Isfahan, Iran. \\ 2. Department of Nursing, School of Nursing, Arak University of Medical Sciences, Arak, Iran. \\ 3. Department of Toxicology, Payam Noor University, Arak, Iran.
}

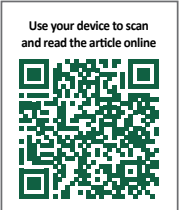

Citation: Bahranifard A, Rahzani K, Maleki Rad AK, Malekpour M. Evaluate Management Performance and the Degree of Readiness Hospital Emergency in Critical Situations. Health in Emergencies and Disasters Quarterly. 2021; 6(3):191-196 http://dx.doi. org/10.32598/hdq.6.3.393

: http://dx.doi.org/10.32598/hdq.6.3.393

Article info:

Received: 10 Dec 2020

Accepted: 23 Feb 2021

Available Online: 01 Apr 2021

\section{Keywords:}

Hospital emergency, Crisis management, Health, Medical emergencies, Accidents, Disasters

\begin{abstract}
Background: Hospitals, especially their emergency departments, are among the first health systems affected by accidents and disasters. Because of its nature and obligation to provide the highest quality services, this department should have protocols for coordination and interaction with other departments and be fully prepared in critical situations. This study aims to evaluate the disaster preparedness of the Emergency Department of Shahid Motahari Hospital in Isfahan Province, Iran.

Materials and Methods: This research is an applied descriptive study conducted in Shahid Motahari Hospital in Fooladshahr City, Isfahan Province, Iran. The study data were collected using the Persian version of the World Health Organization's Hospital Emergency Response Checklist completed through interview and document analysis. The checklist consists of 90 items and 9 domains, including command and control ( 7 items), communications ( 9 items), safety and security (11 items), triage (10 items), surge capacity (13 items), continuity of essential services ( 8 items), human resources (15 items), logistics and supply management (10 items) and post-disaster recovery (7 items). The obtained data were analyzed in SPSS using descriptive statistics over 4 months.
\end{abstract}

Results: The disaster preparedness of the Emergency Department of the Hospital was poor in the human resources domain and good in the communication domain.

Conclusion: The disaster preparedness of the study hospital is at a moderate level. Planning and implementation of practical measures such as holding crisis management courses, establishing a crisis management team, estimating necessary resources, changing the structure, providing human resources for more accurate control and ease of service delivery, maintaining and rapid repairing of equipment, timely triage, and retrofitting hospitals can play an effective role in improving the disaster preparedness of the study emergency department.

\section{"Corresponding Author:}




\section{Introduction}

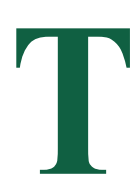

he history of human life and the frequency of accidents and disasters indicate the certainty of disasters. More than 5 million people die each year worldwide due to accidents, which accounts for one-tenth of all deaths and causes tens of millions to refer to emergency medical centers. In addition to incurring high costs on the individuals and society, it causes temporary and permanent disabilities and loss of useful life [1]. One of the most critical dangers that threaten human life in different world countries is the increase in various accidents and related injuries [2]. Accidents and disasters have always caused great concern in people. The main factor of human survival during natural disasters is the provision of healthcare services [3]. One way to reduce the casualties of disasters is to improve the preparedness of hospitals and create a high ability to respond correctly and quickly to accidents, the results of which can reduce the casualties [4]. One of the disasters is COVID-19 which spread rapidly worldwide, and the World Health Organization (WHO) declared it a pandemic on March 11, 2020 [5]. Despite all the vital measures and observing personal and public health, the disease affected many people in different countries, and many were admitted to hospitals [6]. The COVID-19 pandemic challenged the capacity of hospitals, especially the emergency departments, in terms of equipment, supplies, and personnel in a way that had never been experienced before [7]. Evidence has shown that hospitals usually act slowly in preparing for and responding to disasters [8]. The lack of preparedness of hospitals to deal with disasters is one of several factors that directly impact the vulnerability of a country. The crisis and disaster preparedness in different cities of Iran has not been at an acceptable level, such that hospitals in Semnan City were at a low preparedness level [9]. In Tehran, hospitals' preparedness was reported poor to moderate [10]. In Urmia City, Hekmatkhah et al.'s study reported inadequate preparedness of hospitals [11].

The emergency department, as one of the most important wards of hospitals, is facing a large number of patients nowadays. Providing effective services to patients at the right time in this department is possible in case of efficient and effective performance [12]. Crowding has always been a serious problem affecting patient satisfaction in emergency departments [13]. Lack of planning to deal with accidents, the unpreparedness of hospitals, and the lack of trained staff to control the crisis can cause irreparable damage to the country's health care system and the people [14]. Since there is no room for trial and error in crisis management, it is essential to prepare for proper and efficient operation [15]. Health centers, especially the emergency department of hospitals, must be prepared before a disaster occurs to take immediate action and respond in the event of a disaster. In case of any disasters and accidents, the emergency departments of hospitals in each area are the first place to receive medical services. In this study, the disaster preparedness of the Emergency Department of Shahid Motahari Hospital in Isfahan Province, Iran, was investigated from a managerial perspective. The results of this study can provide information to managers to plan and prepare hospitals for a more significant response in the event of unpredictable disasters.

\section{Materials and Methods}

This research is an applied descriptive study conducted in 2016. The study population included all personnel of the Emergency Department of Shahid Motahari Hospital in Fooladshahr City, Isfahan Province, Iran. The data collection tool was a standard hospital emergency response checklist developed by WHO [16] consisting of 90 items and 9 subscales of command and control (7 items), communication ( 9 items), safety and security (11 items), triage (10 items), surge capacity (13 items), continuity of essential services ( 8 items), human resources (15 items), logistics and supply management (10 items), and postdisaster recovery ( 7 items). The Persian version of this checklist has been developed in another study, and its reliability has been reported acceptable [17]. The items are rated on a 3 -point scale from $1=$ due for review to $3=$ in progress, and $5=$ completed. In interpreting the results of each domain, the total score was calculated based on 100 points. To determine the overall score of the department, the scores of each domain were summed up and divided into three categories: very poor (score 0-20), poor (score 20-40), moderate (score 40-60), good (score 60-80), and very good (score 80-100) [18].

After obtaining necessary permits from competent authorities (Vice-Chancellor for Research, University President, and Hospital Manager), the researcher directly referred to the emergency department of the hospital and asked the questions in the checklist from the participants (Secretary of the Crisis Committee, Head Nurse, Emergency Department Manager, Nurse, Emergency Nurse Aide, and Hospital Manager). The collected data were then analyzed. 


\section{Results}

The results showed that the disaster preparedness of the Emergency Department of Shahid Motahari Hospital was poor in the human resource domain but good in the communication domain (Table 1 and Figure 1). The mean score of disaster preparedness based on the WHO checklist was reported as 28.75 , indicating that the preparedness was moderate. Based on the managerial perspective, the mean score of disaster preparedness was reported as 77.98 .

\section{Discussion}

Hospitals, as the first centers for the injured people in the event of a disaster, must be prepared to deal with accidents and crises. Disasters cause widespread and serious health damage quickly and put a lot of pressure on health centers. Therefore, planning must be done, measures must be taken, and the necessary resources must be allocated to ensure efficient services [15]. One of the developments in recent years that has had a tremendous impact on the performance of emergency departments is the existence of performance appraisal and monitoring systems. If performance appraisal is done correctly and continuously, it will improve the function of this department and its effectiveness. Disaster preparedness of hospitals is one of the essential factors that directly impact the country's vulnerability.

The purpose of the present study was to investigate the disaster preparedness of the Emergency Department in a hospital in Fooladshahr City, Isfahan Province, Iran, based on the managerial perspective. Results showed that the disaster preparedness of this department was at a moderate level. This result is consistent with the results of Maleki et al., who reported that the disaster preparedness of the hospitals affiliated to Iran University of Medical Sciences in terms of human resources [19] as well as the results of Parsaei et al. [20]. Disaster preparedness in this study was evaluated in 9 domains. The highest preparedness was in the communication domain $(77.8 \%)$. Daneshmandi, in a study, reported that the preparedness of selected hospitals in terms of communication was 54\% [21]. Parsaei et al. reported that the preparedness in communication was at a moderate level [20], although according to Davab, even 99\% preparedness is not enough to deal with disasters [20]. The lowest emergency preparedness level in the study hospital was related to human resources $(2.8 \%)$. Vali, in a study,

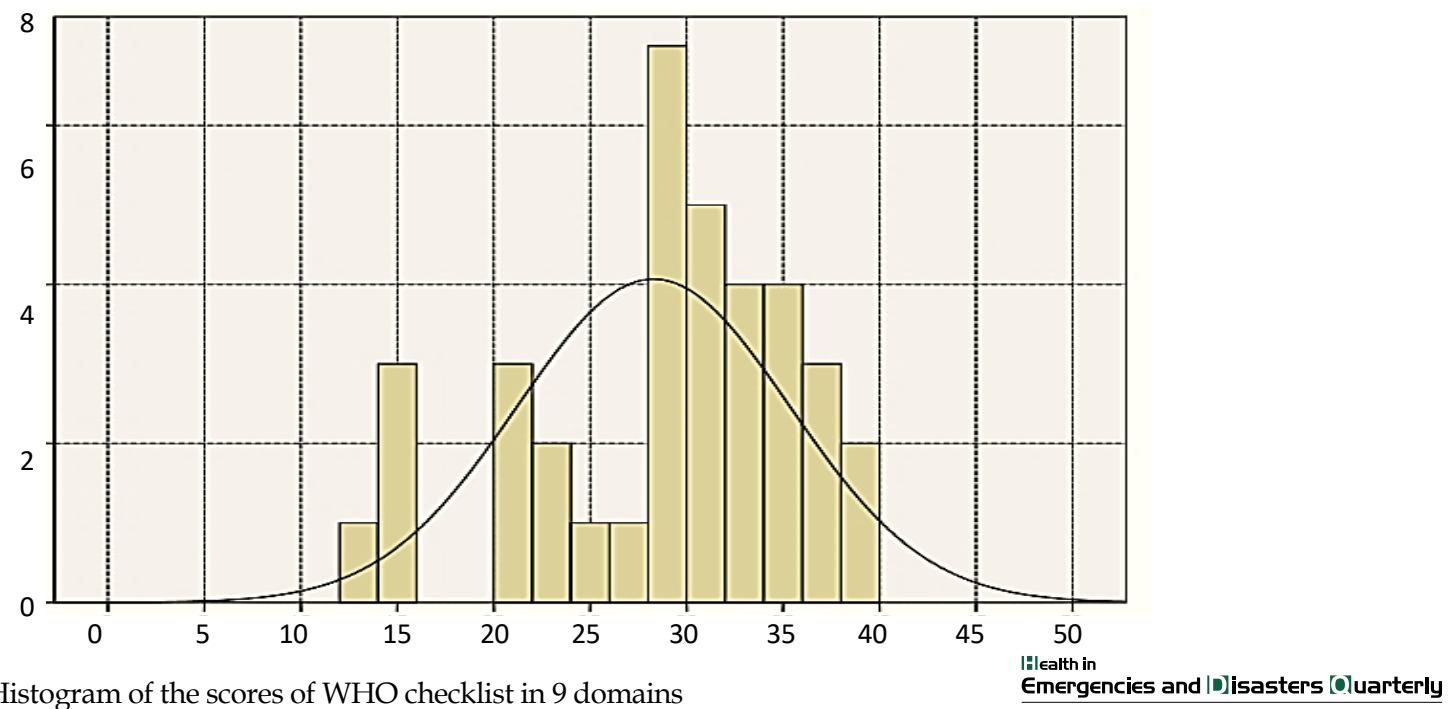

Figure 1. Histogram of the scores of WHO checklist in 9 domains

Table 1. Mean scores of WHO checklist in 9 domains

\begin{tabular}{ccccccccc}
\hline $\begin{array}{c}\text { Command } \\
\text { and Control }\end{array}$ & $\begin{array}{c}\text { Communi- } \\
\text { cation }\end{array}$ & $\begin{array}{c}\text { Safety and } \\
\text { Security }\end{array}$ & Triage & $\begin{array}{c}\text { Surge } \\
\text { Capacity }\end{array}$ & $\begin{array}{c}\text { Continuity } \\
\text { of Essential } \\
\text { Services }\end{array}$ & $\begin{array}{c}\text { Human } \\
\text { Resource }\end{array}$ & $\begin{array}{c}\text { Logistics and } \\
\text { Supply Man- } \\
\text { agement }\end{array}$ & $\begin{array}{c}\text { Post-disaster } \\
\text { Recovery }\end{array}$ \\
\hline $75 \%$ & $77.8 \%$ & $54.4 \%$ & $47.2 \%$ & $38.9 \%$ & $58.3 \%$ & $19.8 \%$ & $41.7 \%$ & $69.4 \%$ \\
\hline & & & & & & $\begin{array}{c}\text { Illealth in } \\
\text { Emergencies and [D]isasters [O]uarterly }\end{array}$ \\
\hline
\end{tabular}

The highest level of hospital emergency preparedness in critical situations was related to communication, and the lowest level of emergency preparedness was related to human resources, which is marked with an asterisk in the table. 
reported that $50 \%$ of the studied emergency departments were at a good level in terms of human resources, and $50 \%$ were at a moderate level [22].

Facilities, equipment, human resources, and ancillary spaces for standard management of the emergency department should be considered in advance [23]. The prompt and appropriate response can play an essential role in reducing the harmful effects of disasters and accidents on physical health and their psychological effects. Preparedness is an essential part of sustainable development, emphasizing the implementation of the required measures. Despite efforts and extensive advances in hospital preparedness for disaster management, many hospitals are not sufficiently prepared for disasters and face many challenges [24].

Accidents are one of the leading and avoidable causes of disability and death in the world. Accident-related injuries will be the second leading cause of disability in developing countries and the third leading cause of death and disability worldwide by 2020 . These injuries account for $12 \%$ of the disease burden in the world [25]. With the increase in road traffic accidents, this rate is expected to increase to 8 million deaths per year in 2020. Awareness of the dimensions of accidents is vital for health policymakers [26]. Lack of preparedness for disasters has led to unsustainable development in communities and heavy losses and damages to people. Iran is 1000 times more vulnerable to earthquakes than the United States and 100 times more vulnerable than Japan. Aside from the irreparable damage that disasters, including earthquakes, cause, the lack of preparedness for an appropriate and effective response to them can be the beginning of a painful tragedy [27]. Health service systems must also be able to provide a coordinated response in the event of a disaster and to effectively plan and implement programs to reduce damage and response time and improve preparedness. Response time is one of the main factors in reducing the irreparable consequences of injuries in accidents [28]. If hospitals fail to respond adequately to natural and man-made disasters or protect people from harm, they will feel insecure, and society will lose its stability [29]. Since the study hospital was affiliated with Zobahan Company, responsible for supplying human resources, the hospital had inadequate preparedness in the human resource domain. This is while human resources are one of the essential pillars in the health sector, and providing human resources from organizations such as the Red Crescent or employing college students could play an essential role in promoting the hospital status. Managers of hospitals can play a crucial role in crisis management by using voluntary services [30].

\section{Conclusion}

Overall, the results showed good disaster preparedness of the study hospital. The results can provide the authorities with the strengths and weaknesses of the hospital so that, if necessary, they can carry out medical and emergency planning and identify the strengths and capacities of the hospital. Optimal preparedness of medical centers can calm patients and staff and provide good quality medical services and procedures. Therefore, it must always be considered in achieving the objectives of healthcare both in normal conditions and in crisis. Based on the results and the importance of emergency departments in urban hospitals in controlling disasters, planning, and implementation of practical measures such as holding crisis management courses, forming a crisis management team, estimating necessary resources, changing the structure, providing human resources for more accurate control and ease of service delivery, maintaining and rapid repair of equipment, timely triage and retrofitting hospitals can play an effective role in improving the disaster preparedness of the study emergency department.

\section{Ethical Considerations}

\section{Compliance with ethical guidelines}

All ethical principles are considered in this article. The participants were informed of the purpose of the research and its implementation stages. They were also assured about the confidentiality of their information and were free to leave the study whenever they wished, and if desired, the research results would be available to them. Written consent has been obtained from the subjects. principles of the Helsinki Convention were also observed.

\section{Funding}

This study was extracted from the $\mathrm{PhD}$. dissertation of the first author at the Department of Crisis Management, School of Natural Hazard Management, University of Isfahan, Isfahan.

\section{Authors' contributions}

Conceptualization and supervision: Kobra Rahzani, Akbar Maleki Rad; Methodology: Mokhtar Malekpour; Writing - review and editing: All Authors; Data collection, data analysis, financial resources, resources, research, and writing - original draft: Asma Bahranifard.

\section{Conflict of interest}

The authors declared no conflict of interest. 


\section{Acknowledgments}

All authors want to thank Professor Rahzani and Maleki Rad, and the staff of Shahid Motahari Hospital in Fooladshahr for their help.

\section{References}

[1] Abdolvand M, Monfared AB, Khodakarim S, Farsar AR, Golmohammadi A, Safaei A. [Evaluation of accidents and incidents at injury registered in medical centers affiliated to Shahid Beheshti University of Medical Sciences (2012- 2013) (Persian)]. Journal of Safety Promotion and Injury Prevention. 2014; 2(1):65-72. [DOI:10.15412/J.HDQ.09010302]

[2] Moradi A, Rahmani K. Trend of traffic accidents and fatalities in iran over 20 years (1993-2013) (Persian)]. Journal of Mazandaran University of Medical Sciences. 2014; 24(119):223 34. http:/ /jmums.mazums.ac.ir/article-1-4697-en.html

[3] Khankeh HR. [Disaster hospital preparedness: National program (Persian)]. Tehran: USWR Publications; 2012. https://vct.iums.ac.ir/files/vct/files/ketab_Amadegi_bimarestani final .pdf

[4] Nasiripou RAA, Raeisi P, Mahboubi M. [Border hospita readiness in handling border related crises in Kermanshah province, Iran, 2007 (Persian)]. Journal of Health Administration. 2007; 10(28):41-48. https://www.sid.ir/en/Journal/ViewPaper.aspx?ID=107699

[5] Hosseini SH, Saleh Tabari Y, Assadi T, Ghasemihamedani F, Habibi Saravi R. [Hospitals readiness in response to COVID-19 pandemic in Mazandaran Province, Iran 2020 (Persian)]. Journal of Mazandaran University of Medical Sciences. 2021; 31(196):71-81. http:/ /jmums.mazums.ac.ir/ article-1-15680-en.html

[6] Liao X, Wang B, Kang Y. Novel coronavirus infection during the 2019-2020 epidemic: Preparing intensive care unitsthe experience in Sichuan Province, China. Intensive Care Medicine. 2020; 46(2):357-60. [DOI:10.1007/s00134-02005954-2] [PMID] [PMCID]

[7] Chopra V, Toner E, Waldhorn R, Washer L. How should US hospitals prepare for coronavirus disease 2019 (COVID-19)? Annals of Internal Medicine. 2020; 172(9):621-2. [DOI:10.7326/M20-0907] [PMID] [PMCID]

[8] Khankeh HR, Mohammadi R, Ahmadi F. [Designing a model for health care delivery in the case of natural disasters (Persian)]. Iranian Journal of Nursing. 2010; 20(51):85-96. https://www.sid.ir/fa/journal/ViewPaper. aspx?id=79244

[9] Amiri M, Mohammadi G, Khosravi A, Chaman R, Arabi M, Sadeghi E, et al. [Hospital preparedness of Semnan province to deal with disasters (Persian)]. Journal of Knowledge \& Health. 2011; 6(3):44-9. [DOI:10.7326/M20-0907]

[10] Azadi A, Sahebi A, Tavan H. [The attitudes, knowledge and performance of ilam nurses regarding disaster preparedness (Persian)]. Health in Emergencies and Disasters. 2018; 3(2):10512. http://hdq.uswr.ac.ir/article-1-160-en.html
[11] Hekmatkhah A, Rahimi H, Kamali Aghdam M, Taghavi Shahri M, Sadeghifar J, Hamouzadeh P. [Assessing the preparedness rate againest earthquake risk in hospitals affiliated to urmia university of medical sciences 2011 (Persian)]. Journal of Urmia Nursing and Midwifery Faculty. 2012; 10(2):200-8. http:/ / unmf.umsu.ac.ir/article-1-824-en.html

[12] Hashemi B, Baratloo A, Rahmati F, Forouzanfar MM, Motamedi M, Safari S. Emergency department performance indexes before and after establishment of emergency medicine. Emergency. 2013; 1(1):20-3. [PMID] [PMCID]

[13] Kalantarimeibidi M, Yadollahi A, Esfandiari S. [The effect of education on the knowledge and practice of emergency department's nurses regarding the patients' triage (Persian)]. Iranian Journal of Emergency Medicine. 2014; 1(1):40-4. [DOI:10.7326/ M20-0907]

[14] Mohabati F. [Survey of knowledge, attitude and performance among managers of hospitals affiliated to Tehran University of Medical Sciences about earthquake danger (Persian)] [MSc. thesis]. Tehran: Tehran University of Medical Sciences; 2005.

[15] Nakhaei M, Khankeh HR, Masoumi G, Hosseini MA, ParsaYekta Z. Health management in disasters in Iran: A qualitative study. Health in Emergencies \& Disasters Quarterly. 2015 1(1):33-42. http://hdq.uswr.ac.ir/article-1-78-en.html

[16] World Health Organization Regional Office for Europe. Hospital emergency response checklist (2011). Copenhagen: World Health Organization Regional Office for Europe; 2011. https:/ / www.euro.who.int/en/health-topics/health-emergencies/ from-disaster-preparedness-and-response/publications/2011/ hospital-emergency-response-checklist-2011

[17] Sadeghi-Bazargani H, Azami-Aghdash S, Kazemi A, Ziapour B. Crisis management aspects of bam catastrophic earthquake. Health Promotion Perspectives. 2015; 5(1):3-13. [DOI:10.15171/ hpp.2015.002] [PMCID] [PMID]

[18] Mastane Z, Mouseli L, Jahangiri M, Doost M, Eshghi A. [Strength and weakness of crisis management in Hormozgan Medical University's Hospitals (Persian)]. Journal of Fasa University of Medical Sciences. 2012; 1(4):244 50. http:/ /jabs.fums. ac.ir/article-1-84-en.html

[19] Maleki M, Shojaei P. [The preparation of educational hospitals of Iran University of Medical Sciences in dealing with the disasters regarding security (Persian)]. Journal of Health Administration. 2007; 10(28):65-70. http://jha.iums.ac.ir/article1-32-fa.html

[20] Parsaei M, Khankeh H, Habibi Saravi R, Masoumi G, Hosseini SH. [Hospital disaster preparedness in Mazandaran Province, Iran 2017 (Persian)]. Journal of Mazandaran University of Medical Sciences. 2019; 28(168):108-17. http:/ /jmums.mazums. ac.ir/article-1-12012-en.html

[21] Daneshmandi M, Amiri H, Vahedi M, Farshi M. [Assessing level of Preparedness for disaster in hospitals of a selected medical sciences university-2009 (Persian)]. Journal Mil Med. 2010; 12(3):167-71. http:/ / militarymedj.ir/article-1-735-en.pdf

[22] Vali L. [Assessment of structure of emergency units in children specialized hospitals in Tehran city in 2001 (Persian)]. Paper presented at: First Scientific and Research Congress on Relief and Rescue Management. 22 February 2003; Tehran, Iran. https:// civilica.com/doc/8445/ 
[23] Aminizadeh M, Farrokhi M, Ebadi A, Masoumi GR, Kolivand $\mathrm{P}$, Khankeh HR. Hospital management preparedness tools in biological events: A scoping review. Journal of Education and Health Promotion. 2019; 8:234. [DOI:10.1197/j. aem.2006.05.007] [PMID] [PMCID]

[24] Aminizadeh M, Farrokhi M, Ebadi A, Masoumi G, Kolivand $\mathrm{P}$, Khankeh $\mathrm{H}$. Hospital preparedness challenges in biological disasters: A qualitative study. Disaster Medicine and Public Health Preparedness. 2020; 1-5. [DOI:10.1017/ dmp.2020.434] [PMID] [PMCID]

[25] Maracy MR, Tabaresfahani M. [The burden of road traffic injuries in Isfahan, Iran in 2010 (Persian)]. Journal of Kerman University of Medical Sciences. 2013; 20(5):505-19. http:// jkmu.kmu.ac.ir/article_16373.html

[26] Khazaei S, Mazharmanesh S, Khazaei Z, Goodarzi E, Mirmoini R, Mohammadian-Hafshejani A, et al. [An epidemiological study on the incidence of accidents in the Hamadan province during 2009 to 2014 (Persian)]. Pajouhan Scientific Journal. 2016; 14(2):8-16. http://psj.umsha.ac.ir/article1-169-en.html

[27] Ganjehi S, Omidvar B, Malekmohammadi B, Norouzi Kh. Analysis and modeling of safety parameters for selection of optimal routes in emergency after an earthquake: Case of $13^{\text {th }}$ Aban Neighorhood in Tehran. Health in Emergencies and Disasters. 2013; 1(1):59-75. https://www.sid.ir/en/journal/ ViewPaper.aspx?ID=441829

[28] Delshad V, Borhani F, Khankeh H, Abbaszadeh A, Sabzalizadeh S, Moradian MJ, et al. The effect of activating early warning system on Motahari Hospital preparedness. Health in Emergencies and Disasters. 2015, 1(1):3-8. http://hdq uswr.ac.ir/article-1-83-en.html

[29] Tavakoli N, Mousavi M. Functional safety status in Isfahan private hospitals in response to disasters in 2015. Health in Emergencies and Disasters. 2017; 2(3):125-32 [DOI:10.18869/ nrip.hdq.2.3.125]

[30] Aminizadeh M, Eslamishahr Babaki M, Beyramijam M, Aminizadeh $\mathrm{M}$, Sheikhbardsiri $\mathrm{H}$. Prioritizing motivational and satisfactorily factors of volunteer medical and health personnel in natural disasters. Health in Emergencies and Disasters. 2016; 1(2):79-88. http:/ /hdq.uswr.ac.ir/article-1-58-en.html 